\begin{tabular}{|c|c|c|c|}
\hline \multirow{3}{*}{$\begin{array}{r}\text { Case Reports in } \\
\text { Gastroenterology }\end{array}$} & Case Rep Gastroenterol 2017; & & \multirow[b]{2}{*}{$\begin{array}{l}\text { Karger } \\
\text { Open access }\end{array}$} \\
\hline & $\begin{array}{l}\text { DOI: 10.1159/000480374 } \\
\text { Publisned onlIne: September 15, } 2017\end{array}$ & $\begin{array}{l}\text { (c) } 2017 \text { The Author(s) } \\
\text { Published by S. Karger AG, Basel } \\
\text { www.karger.com/crg }\end{array}$ & \\
\hline & $\begin{array}{l}\text { This article is licensed under the } \\
\text { International License (CC BY-NC) (ht } \\
\text { Usage and distribution for commercial }\end{array}$ & $\begin{array}{l}\text { mons Attribution-NonCommercial } 4.0 \\
\text { ger.com/Services/OpenAccessLicense). } \\
\text { quires written permission. }\end{array}$ & \\
\hline
\end{tabular}

\title{
Preoperative Diagnosis and Surgical Approach of Appendiceal Mucinous Cystadenoma: Usefulness of Volcano Sign
}

\author{
Masahiro Shiihara Takeshi Ohki Masakazu Yamamoto \\ Department of Surgery, Institute of Gastroenterology, Tokyo Women's Medical University, \\ Tokyo, Japan
}

\section{Keywords}

Volcano sign · Laparoscopic surgery · Appendiceal mucinous cystadenoma

\begin{abstract}
We report a case of appendiceal mucinous cystadenoma that was successfully diagnosed preoperatively and treated by laparoscopic resection. We could find volcano sign on colonoscopy and cystic lesion without any nodules at the appendix on computed tomography (CT). Without any malignant factors in preoperative examinations, we performed laparoscopic appendectomy including the cecal wall. We could avoid performing excessive operation for cystadenoma with accurate preoperative diagnosis and intraoperative finding and pathological diagnosis during surgery. Appendiceal mucocele is a rare disease that is divided into 3 pathological types: hyperplasia, cystadenoma, and cystadenocarcinoma. The surgical approaches for it remain controversial and oversurgery is sometimes done for benign tumor, because preoperative diagnosis is difficult and rupturing an appendiceal tumor results in dissemination. Based on our study, volcano sign on colonoscopy and CT findings were important for the preoperative diagnosis of appendiceal mucocele. Furthermore, we think that laparoscopic resection will become a surgical option for the treatment of appendiceal mucocele.




\section{Case Reports in Gastroenterology}

Case Rep Gastroenterol 2017;11:539-544

DOI: $10.1159 / 000480374$

c 2017 The Author(s). Published by S. Karger AG, Basel www.karger.com/crg

Shiihara et al.: Preoperative Diagnosis and Surgical Approach of Appendiceal Mucinous Cystadenoma: Usefulness of Volcano Sign

\section{Introduction}

Appendiceal mucinous cystadenoma is a relatively rare disease; it is one type of appendiceal mucocele. Appendiceal mucocele can be divided into 3 pathological types: mucosal hyperplasia, mucinous cystadenoma, and mucinous cystadenocarcinoma. Rupturing an appendiceal tumor usually results in dissemination of these cells, a condition known as pseudomyxoma peritonei. The treatment for appendiceal mucocele is typically surgical resection. Surgical approaches for appendiceal mucocele vary from simple appendectomy to right hemicolectomy with lymph node dissection depending on their malignancy. However, due to the difficulty in differentiating cystadenoma from cystadenocarcinoma before surgery, oversurgery is often done for cystadenoma. Thus, the surgical approaches for it still remain controversial. In preoperative examinations, volcano sign is a specific finding of appendiceal mucocele. Nodules in the cyst or dilatation of lymph nodes are said to be malignant factors. Here, we report a case of appendiceal mucinous cystadenoma that was successfully diagnosed before surgery and treated by laparoscopic resection. Recognizing volcano sign and the absence of malignant factors preoperatively, plus intraoperative pathological diagnosis allowed us to avoid operating excessively for benign appendiceal mucocele.

\section{Case Report}

The patient was an 85-year-old male. He had a positive screening fecal occult blood test, so he was referred to our institute for further examination and treatment. His height and weight were $168 \mathrm{~cm}$ and $60 \mathrm{~kg}$. His general condition was good and he had no weight loss. He had no anemia (Hb: $12.7 \mathrm{~g} / \mathrm{dL}$ ), malnutrition (Alb: $4.3 \mathrm{~g} / \mathrm{dL}$, CHE: $284 \mathrm{U} / \mathrm{L}$ ), or abnormal laboratory data including tumor markers (carcinoembryonic antigen: $3.3 \mathrm{ng} / \mathrm{mL}$, carbohydrate antigen 19-9: $15 \mathrm{U} / \mathrm{mL}$ ). He had hypertension and postoperative gallbladder stone. A subsequent colonoscopy revealed a submucosal tumor $2 \mathrm{~cm}$ in diameter at the cecum with cushion sign and volcano sign (Fig. 1). The surface of the tumor looked intact. Abdominal computed tomography (CT) revealed dumbbell-like encapsulated cystic lesion at the cecum (Fig. 2). It was internally uniform, and neither swollen lymph nodes nor intracystic nodules were detected. Based on a diagnosis of appendiceal mucinous cystadenoma, the patient underwent laparoscopic surgery.

With the patient in a supine position with the legs apart, a 12-mm trocar was introduced in the umbilical part and pneumoperitoneum was then established. Another 12-mm trocar was introduced in the left upper abdomen and 5-mm trocars in the left and right lower abdomen. Laparoscopic visualization demonstrated the entirely dilated appendix. Further laparoscopic exploration did not reveal ascites or swollen lymph nodes. The tip of the appendix could not be revealed because it adhered tightly to the posterior wall of the cecum. So, we first dissected the root of the appendix including the cecal wall using Endo-GIA ${ }^{\mathrm{TM}}$ (Covidien). Then, the retrograde approach was undertaken to the tip of the appendix. Finally, the tumor was carefully extracted from the umbilical part using Endo-catcher ${ }^{\mathrm{TM}}$ (Covidien). Pathological diagnosis during surgery revealed that no malignant cells existed and surgical margin was negative. So, lymph node dissection was not performed.

A gross pathologic examination demonstrated a $7.5 \times 4.0 \mathrm{~cm}$ cystic structure with mucoid fluid. Microscopic examination revealed that the structure had a mildly atypical epithelium, compatible with the diagnosis of mucinous cystadenoma (Fig. 3). There were no complications. The patient was then discharged on the 7 th postoperative day. 
Shiihara et al.: Preoperative Diagnosis and Surgical Approach of Appendiceal Mucinous Cystadenoma: Usefulness of Volcano Sign

\section{Discussion}

Appendiceal mucocele was first described by Rokitansky [1]. It is the condition caused by dilation of a lumen as a result of an accumulation of mucus. Its incidence ranges between 0.2 and $0.3 \%$ of all resected appendices [2,3]. Appendiceal mucocele can be divided into 3 pathological types: mucosal hyperplasia, mucinous cystadenoma, and mucinous cystadenocarcinoma. It is reported that the ratio of each incidence is about 2:5:1 [4].

As for the extent of tumor resection, simple appendectomy is sufficient for mucosal hyperplasia and mucinous cystadenoma. But if a cystadenocarcinoma is present, ileocecal resection or right hemicolectomy with lymph node dissection is indicated [5-7]. Recently, some authors have reported that right hemicolectomy provides no survival advantage [8]. Dhage-Ivatury [1] have suggested several factors about the selection of the type of surgery: (A) whether or not a mucocele is perforated, (B) whether the base of the appendix is involved in the process, and (C) whether there are positive lymph nodes of mesoappendix and ileocolic artery [3].

However, it is difficult to differentiate benign tumor as mucosal hyperplasia and mucinous cystadenoma from mucinous cystadenocarcinoma before surgery. Thus, there is a tendency that an oversurgery is performed to hyperplasia and mucinous cystadenoma. Furthermore, if it is ruptured and the filling turns up in the peritoneal cavity during surgery, there is high probability that pseudomyxoma peritonei will develop. The prognosis is so bad, 5-year-survival is $53-75 \%$ and 10 -year-survival is $10-32 \%$ [9, 10]. So, some surgeons think that open surgery should be favored against laparoscopy [11].

In our case, we found volcano sign, which is characteristic of appendiceal mucocele, and there were no malignant factors such as intracystic nodules or swollen lymph nodes in preoperative examinations [12]. We judged that lymph node dissection or right hemicolectomy were not needed. In operation, to ensure the surgical margin, we performed appendectomy including the cecal wall. Thus, we could avoid oversurgery to mucinous cystadenoma by accurate preoperative diagnosis.

In operation, it is so important not to perforate a tumor. In our case, we first could not demonstrate the whole of the tumor. We first dissected the root of the appendix and approached retrogradely. Furthermore, we made sure not to take the tumor by laparoscopic forceps and extracted it using a plastic bag to avoid adhesion of mucus to the peritonea. However, the clinical benefit of laparoscopic resection of appendiceal mucocele is presently unclear. It can be done safely by framing in order not to perforate a tumor. We think that laparoscopic resection will become a surgical option for the treatment of appendiceal mucocele.

\section{Conclusion}

Volcano sign on colonoscopy and CT findings were important for the preoperative diagnosis of appendiceal mucocele. The surgical approach to appendiceal mucocele is controversial, but laparoscopic resection will become a surgical option. 


\section{Case Reports in Gastroenterology}

(C) 2017 The Author(s). Published by S. Karger AG, Basel www.karger.com/crg

Shiihara et al.: Preoperative Diagnosis and Surgical Approach of Appendiceal Mucinous Cystadenoma: Usefulness of Volcano Sign

\section{Statement of Ethics}

The study protocol was approved by our institute's committee on human research. The patient's information was protected and collected in a form that could not be identified. Informed consent was obtained from the patient for publication of this case.

\section{Disclosure Statement}

We declare that we have no conflict of interest.

\section{References}

1 Dhage-Ivatury S, Sugarbaker PH: Update on the surgical approach to mucocele of appendix. J Am Coll Surg 2006;202:680-684.

2 Higa E, Rosai J, Pizzimbono CA, Wise L: Mucosal hyperplasia, mucinous cystadenoma, mucinous cystadenocarcinoma of the appendix. A re-evaluation of appendiceal mucocele. Cancer 1973;32:15251541.

3 Soweid AM, Clarkston WK, Andrus CH, Janney CG: Diagnosis and management of appendiceal mucoceles. Dig Dis 1998;16:183-186.

4 Aho AJ, Heinonen R, Lauren P: Benign and malignant mucocele of the appendix. Histological types and prognosis. Acta Chir Scand 1973;139:392-400.

5 Kahn M, Friedman IH: Mucocele of the appendix: diagnosis and surgical management. Dis Colon Rectum 1979;22:267-269.

-6 Gonzalez-Moreno S, Sugarbaker PH: Right hemicolectomy does not confer a survival advantage in patients with mucinous carcinoma of the appendix and peritoneal seeding. Br J Surg 2004;91:304-311.

7 Gough DB, Donohue JH, Schutt AJ, Gonchoroff N, Goellner JR: Pseudomyxoma peritonei: long-term patient survival with an aggressive regional approach. Ann Surg 1994;219:112-119.

-8 Smith JW, Kemeny N, Caldwell C, Banner P, Sigurdson E: Pseudomyxoma peritonei of appendiceal origin. The Memorial Sloan-Kettering Cancer Center experience. Cancer 1992;70:396-401.

-9 Gonzalez-Moreno S, Shmookler BM, Sugarbaker PH: Appendiceal mucocele; contraindication to laparoscopic appendectomy. Surg Endosc 1998;12:1177-1179.

10 Chiou YY, Pitman MB, Hahn PF, et al: Rare benign and malignant appendiceal lesions: spectrum of computed tomography findings with pathologic correction. J Comput Assist Tomogr 2003;27:622-625.

11 Hirata I: Submucosal tumor (SMT). Rinshoshoukakinaika 2011;26:1653-1662 (Japanese literature).

12 Ponsky JL: An endoscopic view of mucocele of the appendix. Gastrointest Endosc 1976;23:42-43.

13 Hamilton DL, Stormont JM: The volcano sign of appendiceal mucocele. Gastrointest Endosc 1989;35:453-456.

14 Rokitansky CF: A Manual of Pathological Anatomy, English transition of the Vienna edition Vol. 2. Balanchard \& Lea, Philadelphia. 1855, p 89.

15 Landen S, Bertrand C, Maddern GJ, Herman D, Pourbarix A, de Neve A, et al: Appendiceal mucoceles and pseudomyxoma peritonei. Surg Gynecol Obstet 1992;175:401-404. 


\section{Case Reports in Gastroenterology}

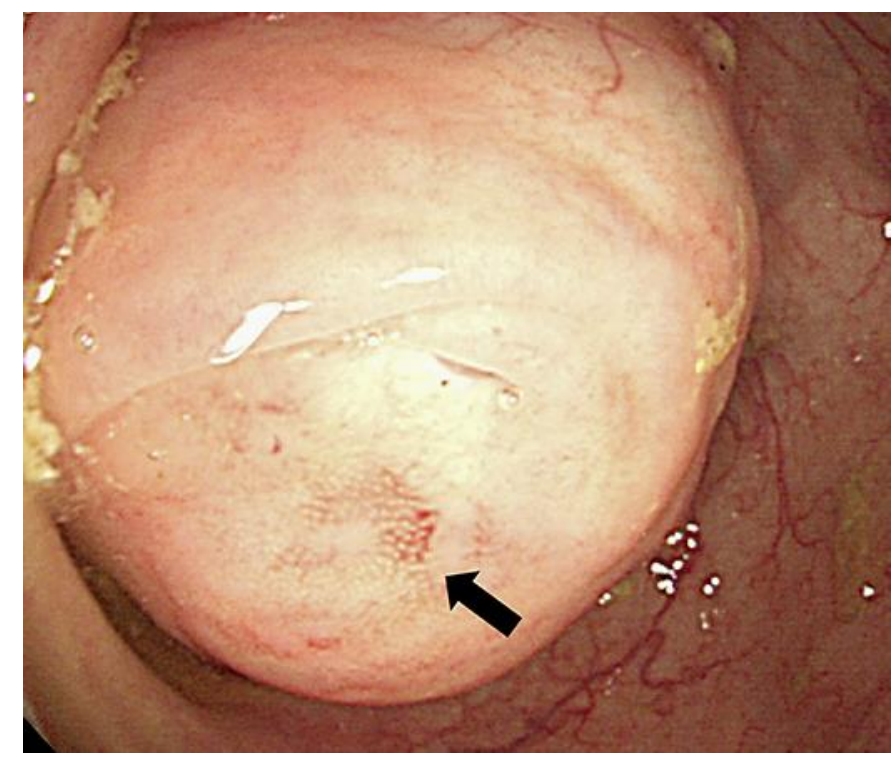

Fig. 1. Colonoscopy demonstrated a submucosal tumor of $2 \mathrm{~cm}$ in diameter at the cecum with cushion sign [13]. Appendiceal orifice of the tumor was visible in the center of the mound covered by normal-appearing mucosa (volcano sign: arrow) $[14,15]$.

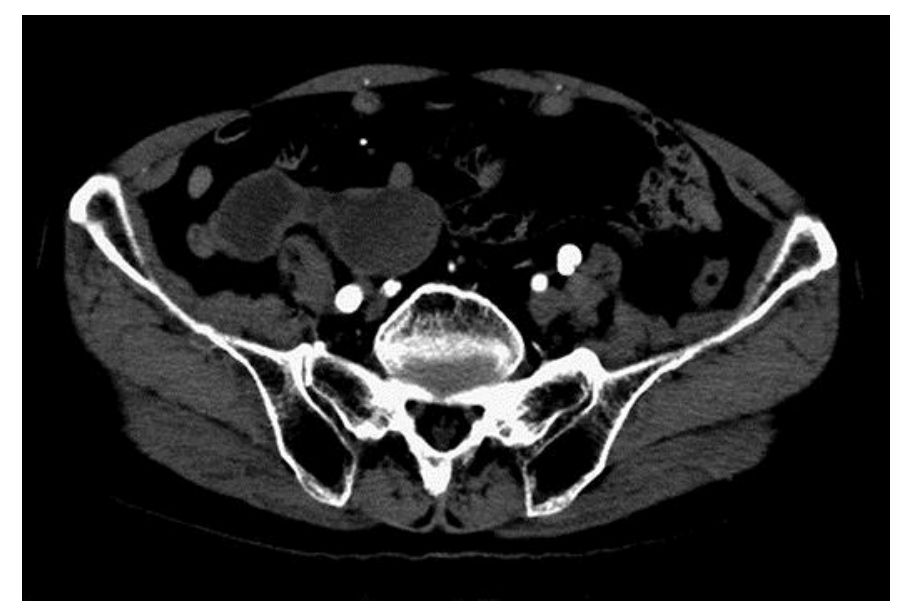

Fig. 2. Abdominal CT showed dumbbell-like encapsulated cystic lesion at the cecum. 


\begin{tabular}{ll|l} 
Case Reports in & \begin{tabular}{l} 
Case Rep Gastroenterol 2017;11:539-544 \\
\cline { 2 - 3 } Gastroenterology
\end{tabular} & $\begin{array}{l}\text { DO } 2017 \text { The Author(s). Published by S. Karger AG, Basel } \\
\text { www.karger.com/crg }\end{array}$ \\
\cline { 2 - 3 } & $\begin{array}{l}\text { Shiihara et al.: Preoperative Diagnosis and Surgical Approach of Appendiceal Mucinous } \\
\text { Cystadenoma: Usefulness of Volcano Sign }\end{array}$
\end{tabular}

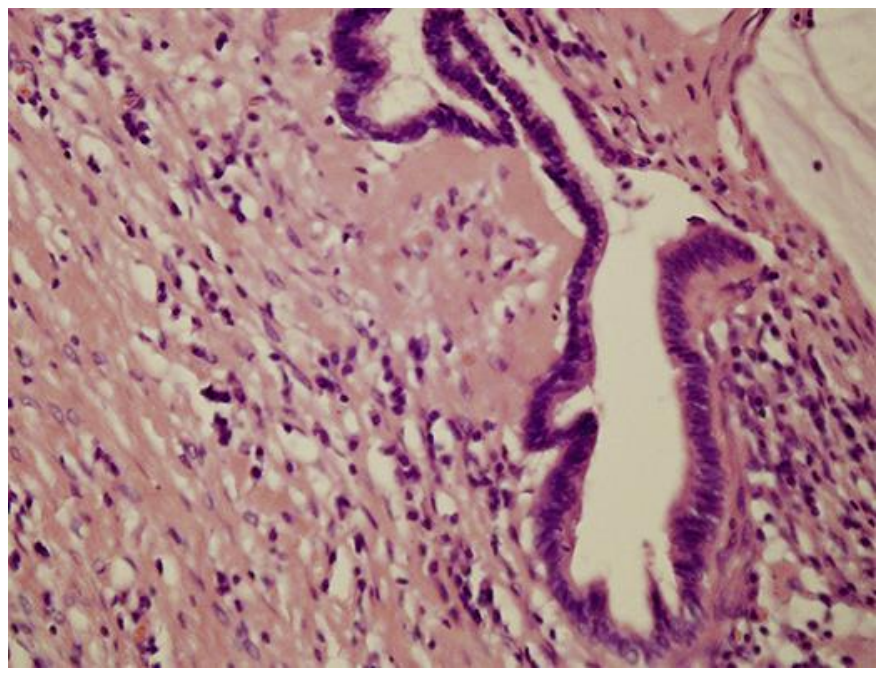

Fig. 3. Microscopic examination revealed that the structure had a mildly atypical epithelium. 